\title{
Reference values of IL-6 and TNF $\alpha$ in Mexican adolescents by BMI
}

\author{
R. V. Pardo-Morales ${ }^{1}$, M. G. Zúñiga-Torres ${ }^{2}$, B. E. Martínez-Carrillo² ${ }^{2}$ S. Gómez-Martínez ${ }^{3}$, \\ A. Marcos $^{3}$ and R. Valdés-Ramos ${ }^{2}$ \\ ${ }^{1}$ Hospital of Gynecology and Obstetrics, Instituto Materno Infantil del Estado de México, Mexico, ${ }^{2}$ Center for Research and \\ Graduate Studies in Health Sciences, Faculty of Medicine, Universidad Autónoma del Estado de México, Mexico and \\ ${ }^{3}$ Instituto de Ciencia y Tecnología de los Alimentos y Nutrición (ICTAN-CSIC), Madrid, Spain
}

IL-6 is a cytokine mediator in inflammation and stress, produced by different cell groups, including adipocytes, it has been found associated with BMI ${ }^{(1)}$. TNF $\alpha$ is a cytokine produced by monocytes, lymphocytes, adipose tissue and muscle ${ }^{(2)}$, it is able to increase production of IL-6, the adipose tissue of obese individuals have an over-expression of mRNA for TNF $\alpha$ receptor 2 in relation to BMI ${ }^{(3)}$.

The aim of the present study was to provide reference values of some cytokines in Mexican adolescents by BMI status. A crosssectional sample of 115 adolescents aged 12-18 years, from the city of Toluca, Mexico, was measured for weight and height for BMI calculation, they were divided into non-overweight, risk of overweight/overweight according to Centers for Disease Control (CDC) paediatric criteria. IL-6 and TNF $\alpha$ from stimulated supernatant were analysed with Human Th1-Th2 cytokine Cytometric Bead Array II kit (BD Biosciences Pharmigen, San Diego, CA, USA), and detected by flow cytometry (Facs Diva, BD $\left.{ }^{\circledR}\right)^{(4)}$.

\begin{tabular}{|c|c|c|c|c|c|c|c|c|}
\hline & \multicolumn{4}{|c|}{ Male } & \multicolumn{4}{|c|}{ Female } \\
\hline & \multicolumn{2}{|c|}{ Non-overweight } & \multicolumn{2}{|c|}{ Risk of overweight and overweight } & \multicolumn{2}{|c|}{ Non-overweight } & \multicolumn{2}{|c|}{ Risk of overweight and overweight } \\
\hline & Mean & $\mathrm{SD}$ & Mean & $\mathrm{SD}$ & Mean & SD & Mean & SD \\
\hline IL-6 (pg/ml) & 576 & 750 & 112 & 67.1 & 740 & 1070 & 621 & 859 \\
\hline $\mathrm{TNF} \alpha(\mathrm{pg} / \mathrm{ml})$ & 58.9 & 39.0 & 45.0 & 6.3 & 89.8 & 116 & 56.9 & 35.0 \\
\hline
\end{tabular}

As we show, in subjects with risk of overweight or overweight values of both IL-6 and TNF $\alpha$ are lower in comparison with nonoverweight adolescents; however, statistical differences were not found. This information may be used in the future as both, reference values and comparison points by gender, BMI status, ethnic and technique of determination.

1. Hotamisligil GS, Arner P, Atkinson RL et al. (1997) Diabetes 46, 451-5.

2. Recasens M, Ricart W \& Fernández-Real JM (2004) Obesidad e Inflamación. Rev Med Univ Navarra 48, 49-54.

3. Fried SK, Bunkin DA \& Greenberg AS (1998) J Clin Endocrinol Metab 83, 1313-1316.

4. Rodríguez-Caballero A, García-Montero AC, Bueno C et al. (2004) Lab Invest 84, 1387-1398. 